\title{
Angst in Albee's A Delicate Balance
}

\author{
Kadhim Hatem Kaibr \\ English Dept, School of Foreign Languages, Huazhong University of Science and Technology, Hubei Province, Wuhan \\ City, China \\ Jingjing Guo \\ English Dept, School of Foreign Languages, Huazhong University of Science and Technology, Hubei Province, Wuhan \\ City, China
}

\begin{abstract}
The works of Albee reflected the state of rejection and indignation that invaded the American society in the middle of the last century as manifested in the infiltration of trade forms and industrialization into all fields of life. His first works, including in his play A Delicate Balance Albee focused on the themes of loss and anxiety that the American individual suffered in that period. This paper will try to examine the reasons that drove the main characters in this play to anxiety and loss, and how they lived in complete isolation by their obsession over aging and fear. Also, this paper will touch on the deterioration of relations among family members under the influence of the "American dream" project.
\end{abstract}

Index Terms - aging, angst, fear, loss of self-confidence, Albee, A Delicate Balance

\section{INTRODUCTION}

A Delicate Balance tells the story of the following characters: Agnes is a woman in her late 50s who suffers from the fear of losing her mind. Sensing her role as the point of reference for her family, Agnes tries hard to hide her fear from others to maintain the balance in her family. She not only ignores the presence of her alcoholic sister in her home since her divorce, but also endures the embarrassing situations caused by her husband, Tobias.

Tobias is a few years older than Agnes and suffers from a fear of death. Although he was left emotionally shocked by the death of his young son Teddy several years ago, Tobias strives to maintain his balance and hide his internal conflict and state of anxiety by indulging in alcohol. He also forces Agnes to accept the presence of his friend Harry and his wife Edna in their household.

Claire is the alcoholic younger sister of Agnes, who is not afraid of showing her faults to others. She considers the most honest character in the play. She does lack a harmonious relationship with her sister, which she subjects to constant embarrassment, and even tries provoking Tobias to leave his wife.

Julia is the daughter of Tobias and Agnes, who has already been married and divorced several times in her early 30s. She has lived with her parents since her latest divorce, has a hysterical temper, and is greatly distressed by the presence of her aunt and her father's friend at their home.

Harry and his wife Edna are friends of Tobias and Agnes, who are close to their age. They are suffering from a fear of the unknown, which drove them out of their house and seek solace in Tobias and Agnes's home. Their fear is unknown to the other characters in the play. Harry and Edna themselves do not know the cause of their fear. Agnes is annoyed of staying at home, but reluctantly does so to satisfy the demands of her husband.

The play takes place in the living room of Agnes and Tobias's house. The couple is suffering from loneliness and feels that they can no longer protect their marriage, which they consider meaningless. Claire, who has suffered from a failed marriage and has no friends, is living together with her sister Agnes and her brother-in-law Tobias. Agnes and Tobias's daughter Julia comes to live with them after the failure of her latest marriage. Harry and his wife Edna also live with the couple to cope with their fear of the unknown. All these characters escape from their reality and gather in the house of Tobias and Agnes in search of comfort and safety. However, instead of finding solace, they enter into arguments and are forced to confront their struggles and internal suffering.

\section{FEAR}

Escape from reality and fear of the unknown are the common denominators of all characters in A Delicate Balance. The fear of the unknown, which reflects the state of anxiety experienced by these characters, is embodied in several aspects depending on each character. Agnes, the main female character in the play, suffers from the fear of losing her mind. This phobia controls Agnes because she finds that insanity will help her escape the vacuum in which she lives. “...the belief that I might very easily- as they say- lose my mind one day" (Delicate, p.19).

Agnes strives to hide her phobia from others and maintain the image of a strong woman who is capable of maintaining the bonds within her family. She simultaneously tolerates the harsh words thrown at her by her alcoholic sister Claire and the difficult situation being faced by her daughter Julia. Agnes is also evaluating her marriage with Tobias, who suffers from fear of death and struggles with the same emotional shock that he has not shaken off since the 
death of his son Teddy. In other words, Agnes lives in a state of contradiction and conflict between her fear of madness that controls her thinking and her attempt to hide such conflict from the other living in her home. Agnes's suffering lies in her difficulty of striking a balance between her steadfastness in maintaining a strong personality and behavior and her desire to live in a world of madness. Nilson (1989) argued that "Human life consists of a delicate balance between the options of a consciously willed order and an abandonment of the self to the forces of chaos and dependence" (p.150).

Meanwhile, Tobias suffers from anxiety and fear of death and has never gotten over the death of his son many years ago. Similar to Agnes, Tobias tries to hide his grief and anxiety by drinking alcohol or pretending to be indifferent to others around him. "Capitulating into a sense of order which is in fact no more than mere routine and denial of the force and reality of loss" (Bigsby, 1975, P.294). In this sense, both Agnes and Tobias are having troubles in balancing their internal suffering and fulfilling their duties to others.

After the death of his son Teddy, Tobias has immersed himself in grief that he cannot get rid of or overcome. According to Agnes, their family life has undergone a complete overthrow after the death of Teddy. She thinks that the death of Teddy has killed all signs of a marital relationship with Tobias because her husband has completely isolated himself from his family and his responsibilities to his wife.

Agnes: "It was an unreal time: I thought Tobias was out of love with me-or, rather, was tired of it, when Teddy died, as if it had been the string."

Tobias fears that he would relive the death of his son by entering a new relationship. However, this was not a habit of Tobias's before his son's death. "Tobias's passivity is a choice, not due to some lack of his nature" (Gussow,1999, p. 261).

Tobias and Agnes have their own ways of hiding their fears. On the one hand, Tobias suppresses his internal struggles and denies their existence by avoiding his paternal responsibilities to his family. Even Agnes accuses him of being responsible for the failures of their daughter because he has not shown her the paternal authority that she needs to make the right decisions.

Agnes: "Each time Julia comes, each clockwork time...do you send her back? Do you tell her, Julia, go home to your husband, try it again? Do you? No, you let it...slip" (Delicate, p.100).

On the other hand, Agnes completely avoids discussing her problems with her sister or daughter and refuses to debate about the misfortunes and failures in her family. She applies general rules in her daily behavior as a way to avoid discussing the sad parts of her life with others. For example, she does not see any need to discuss private or public matters at the dining table and she tends to avoid engaging in futile discussions. Bigbsy (1975) stated that "her desire for order eventually makes her deny the reality of what she sees and avoid the responsibility for any deep problem in the household" (p. 295).

Agnes and Tobias use a non-confrontational style when talking to the other characters in the play in hopes that doing so will help them prevent disclosing their fears. Despite their inner fears and memories of an imperfect marriage, Agnes and Tobias work hard to maintain the balance in their family. Each member of the family has endured painful memories and loss throughout their lives, yet tries to hide these feelings and show to others that they are living normal and balanced lives.

Harry and Edna represent another aspect of fear. They have fled their homes and retreated to the house of Tobias and Agnes in search of a feeling of safety that they cannot find in their own home.

Harry: "We can't go back there" (Delicate.47).

Harry and Edna are not aware of the exact cause of their fears. What they only know is that this type of fear does not make them feel secure in their own home. Agnes, as the focal point in her family, was initially reluctant to welcome Harry and Edna into their household because she knew that her family members are facing their own fears and have no space left to accommodate the concerns of other people.

The fear and anxiety being faced by Julia and Claire are manifested in their defeat and fear of facing reality. Claire and Julia are the most defeatist characters in the play who are unable to make their own decisions or establish proper relationships with people inside and outside their homes. Both Claire and Julia find in Tobias and Agnes a safe haven where they can completely avoid the difficulties they face in the outside world. They also find in Agnes and Tobias the mature personality and authority to make decisions. "Julia, the adult child who is unable to sustain a relationship outside her family is incapable of taking a step to alter and improve her relationships within the family. She waits for others to take action" (Gussow, 1999, p. 262).

Paolucci (1972) argued that Julia's return to her parents' home has intensified her difficulties and psychological crisis because she believes that her parents' home is a thing of her past and that her parents cannot help her solve her problems and prevent her from marrying scammers, homosexuals, and gamblers. "...a long-lost dream, the dead past, and in choosing to return, Julia is merely aggravating her already serious emotional difficulties" (p.110). Nielsen (1989) found that Julia's choice and association with such men is not coincidental; he observed that Julia has a psychological tendency to choose those people who cannot maintain marital relations. In this case, Julia sees her parents and her childhood home as a warm place that not only gives her comfort and safety, but also stops her from entering a real marital relationship. She has "a tendency on her part to look for impossible partners so that she has to return to the womb of her parent's house which she cannot bring herself to leave" (p. 153). 
Claire feels threatened by the arrival of Julia, Harry, and Edna in her sister's home. She feels that their arrival may push her into a marginalized position in the house. However, Claire considered the most secure character in the play because she admits that she has given in to her situation and has no desire to change anything. Unlike the other characters in the play, Claire is unrestrained and acts freely without observing public traditions or customs. She has resorted to alcohol as a way of escaping her reality. However, all characters in the play suffer from anxiety, fear, and lack of comfort or safety, and each one of them has entered Tobias and Agnes's house in search of something missing. Each of them lives in a dark world filled with bitter memories and experiences that have caused them frustration, despair, and loss. Harry and Edna's entry to the house marks the turning point of the play. Despite his fear of the unknown, Harry has unmasked the fears of every other character in the play. He and his wife have entered a Tobias's house to hide themselves from their fear of living in their own home. However, they have discovered that everyone in Tobias and Agnes's family is having the same fear and anxiety that they are facing, but in different ways. Therefore, they eventually leave the house and search for another place where they can find safety. Harry and Edna's decision to leave the house has placed Tobias in a dilemma. On the one hand, he does not want them to stay at his home because of their fear. On the other hand, he does not want to disavow his friendship with Harry and appear disrespectful to himself and his friends. With regard to the relationship between the play and its title, Albee explained that "The delicate balance is between what we should be doing and what we ultimately decide we need to do to protect ourselves. I assume that's why I called the play A Delicate Balance" (Gussow, 1999, p 256-257). As mentioned above, Tobias's lack of interest in assuming the decision-maker role in his household can be ascribed to his fear of death. He is afraid of entering new relationships with others to avoid experiencing the same loss that he felt after the death of his son. In other words, Harry and Edna's decision to leave the house has pushed Tobias into a situation where he must decide between stopping his guests from leaving and getting rid of his withdrawal complex and thoughts of irresponsibility. Tobias did not try to stop his guests from leaving until it was too late.

Tobias: "Stay! (Softer) Stay! (Soft, tears) Stay. Please? Stay? (Pause) Stay? Please? Stay?" (Delicate, p. 117).

Tobias's pleas for Harry and Edna to stay reflect his desire to make a decision. Sense of responsibility and decisionmaking ability are long lost to Tobias. According to Paolucci (1972), "He has settled for the illusion of peace. The ordeal, the Terror, is reduced to conventional proportions and buried with all the other failures of the past" (p. 116).

The arrival of Harry and Edna at Tobias's house has given him and his family an opportunity to face and overcome their fears, but they eventually find that they are not yet ready to do so. After the departure of Harry and Edna, Agnes announces that she is still attempting to keep her family stable, although she has completely collapsed from the inside and that her fear of losing her mind has made her believe that she is actually crazy. "Albee recurrent theme of threat, which is posed by reality is dispelled and they eagerly embrace their self-deceptions" (Adler, 2007, p. 84). Unable to face his sense of hesitation and irresponsibility, Tobias is convinced that he has been unable to face his fears and that he has failed to exploit the opportunity to do so. Claire continues to drink alcohol and act indifferent to everything that goes on around her, while Julia retains her childish way of thinking and lack of self-confidence as well as continues retreating to her parents' home every time she faces failure. "People sleep at night because they fear darkness" (Delicate. 150). This statement by Agnes reflects the fear of an individual to face his reality. In this play, Albee argued that individuals sometimes feel that their past lives have been meaningless and that they are too late to fix them. They are left with no choice but to adjust themselves to living and balancing the conflict between their desire to restore the past and their belief that doing so will not allow them to live peacefully in a world filled with feelings of loss and fear of the unknown.

\section{AGING}

Every human being follows almost the same sequence of life; they move from infancy to childhood, to adolescence, to adulthood, to marriage, and for a period of aging. Although each of these phases has its own characteristics and natural conditions, some believe that aging is the most difficult phase of a person's life. From the physiological perspective, man loses much of his activity, strength, and vitality during this phase. By contrast, from the psychological perspective, a man at this phase of life suffers from the vacuum and anxiety of the fate that awaits him. With regard to marital life, partners may suffer from the disintegration of bonds among them and feel that they have been separated from one another. Through A Delicate Balance, Albee touched upon the situation being faced by couples during their aging phase. Albee focused on how an individual can exploit his early life without feeling loss or regret upon reaching the old age because the feeling of remorse for one's past life and attempting to change it despite being too late represent man's inability to compensate for his past mistakes, which pushes him into a situation of loss and frustration.

The main characters in A Delicate Balance are nearing their aging phase and find themselves unable to adapt to a materialistic society. They feel that their past lives have been meaningless and that the feelings they have throughout their lives are all false. Therefore, their lives are filled with isolation, fear, and anxiety about their fate. Although fear is a common concern for all characters in the play, each character faces a different type of fear. For instance, Julia is afraid of maturity and tends to stick to her childish ways of thinking because she is incapable of assuming her responsibilities as a mature woman. Claire is also afraid of facing her reality and tends to fill her vacuum with alcohol. Meanwhile, Tobias and Agnes as well as Harry and Edna, are generally afraid of approaching the old age. 
Harry and Edna run away from their home to escape their feelings of insecurity, the emptiness and loneliness of their family life, and the fear that something is chasing, frightening and making them feel unsafe. Albee did not specifically mention what Harry and Edna were afraid of and merely implied that they were afraid of aging. They are afraid of death and the feeling that their life is starting to run out of their hands. Their decision to leave their home and retreat to the house of Tobias makes them behave like children who are afraid of the dark and need to be embraced. "It symbolizes all the unspeakable fears of modern man, and especially man's fear of being alone and of being unable to communicate basically with any other living creature" (Post, 1969, 164).

Harry's fears of loneliness, a sense of the threat of the unknown, inability to communicate, and inability to face reality all represent the effects of the old age. These fears have pushed him and his wife out of their home and seek solace in Tobias's house.

Harry: “...We got frightened, we got scared, we couldn't stay there, and so, we came here. You're our very best friends" (45).

Harry and Edna have tried to kill such sense of threat by preoccupying themselves with learning the French language and frequently visiting social clubs, but these activities have failed to completely save them from the threat. By sharing their distresses to Tobias and Agnes, Harry and Edna show that they have very limited choices and that their lives are approaching the end. This reality has resulted in a feeling of despair from which they have repetitively tried to escape. They ultimately decide to leave Tobias's house because they cannot find the safety that can save them from the phobia and the threat of reaching the old age.

One of the effects of aging is reflected in the behavior of Tobias. Entering the aging phase has made Tobias live for himself only. His wife, Agnes, always blames him for not fulfilling his role as a father to his daughter and not paying attention to her problems. The passage of time has killed Tobias's feelings as a husband and father. By killing a cat that he has taken care of for a long time, Tobias rids himself of any feelings of love in his life. "Symbolically the story of the cat correlates to the lack of love in Tobias's world, for just as the cat responded indifferently to him, so Tobias responded indifferently to Agnes and Julia" (Roudane,1987,p 113).

The death of the cat also represents the disconnect between the reality and inability of Tobias to keep giving love to those who love him. Tobias has also expressed regret over the killing of his cat, and such regret suggests that he also feels guilty for not being enough for his family, thereby leading to his sense of failure as a father and husband. Tobias's aging stops him from repairing his previous mistakes, thereby leaving him with no choice but to escape his reality by showing surrender and carelessness as well as abandoning his family responsibilities.

Despite Agnes's attempts to improve her role as a mother and shoulder all family responsibilities after Tobias surrenders his role as a husband and father, she also suffers from a fear of madness that is associated with her aging. Therefore, her attempts to maintain balance in her family were only superficial and she cannot find solutions to the fears being suffered by all the members of her family.

Agnes: "when we keep something in shape.... We keep it from falling apart. We do not attempt the impossible. We maintain. We hold" (Delicate. 80).

Julia's tendencies to stay in her childish mold and her fear of becoming a mature woman who is capable of building an independent family all represent her fear of aging. Julia has suffered four failed marriages, and each failure had driven her back to her parents' home because she does not want to stop living in her illusion of a childhood world and she does not want to become a wife and a mother because of her fear of aging. "... so you can look down the hall from the bed and see that Mommy's the door is open" (Bigsby,1975, 92). Moreover, after the death of her brother Teddy, Julia was neglected by her father, who retired from his marital and family life and gave up his parental responsibilities toward her. Her father's and husbands' neglect prompted Julia to remain in a childlike state to make up for her lost childhood, which was taken away from her by the birth of her brother.

Agnes: "Teddy's birth, and how she felt unwanted, tricked ... All the schools we sent her to, and did she fail in them through hate ... or love?"

Similar to Harry and Edna, Julia retreats to her parents' home to feel safe and get rid of her loneliness. However, she is also unable to find what she is looking for because her family is emotionally shattered and unable to tolerate their and others' fears. In this case, through A Delicate Balance, Albee underscored the nature of family relations when parents are nearing the aging phase and how couples during this phase abandon their responsibilities to live in a world of illusion. Albee also highlighted the anxiety and fears that dominate the thinking of aging people as well as their sense of exclusion from the materialistic American society.

\section{CORROSION OF FEELINGS}

A Delicate Balance shows many feelings of loss depending on the circumstances and situation of each character. Agnes lives in a state of conflict between her attempts to maintain her family's balance and her struggle to maintain her mental equilibrium and face her fears of going mad. She lost her youth at age 37 following her marriage to Tobias, after which she discovered that her marital life with him was meaningless. Agnes has faced another feeling of loss when her son died before reaching his adolescence. She has also been deprived of the opportunity to have another child because Tobias stopped having sex with her after the death of Tobias. These reasons have eroded Agnes's feelings until she became deprived of love, and such deprivation serves as the foundation of her other losses. 
Meanwhile, Tobias has entered a world of loss and consequently withdrew himself from his parental role in the family. He feels indifferent to what is happening around him and to the problems being faced by his family, including the return of his daughter Julia and the death of his son Teddy, of which the latter marked a turning point in his life that killed all human feelings inside him.

Julia's four failed marriages have consumed all her feelings as a woman, her self-confidence, and her ability to move from a child's mindset to that of a mature woman. She has chosen to live in a world of illusion inside her parents' home. Similarly, Claire's failure to marry and start a family as well as her alcoholism have killed all her human feelings. Harry and Edna, after a long marriage, have developed a fear of the unknown, have lost their sense of security, and have no other means to address their fears.

Agnes and Tobias's marital relationship started to degrade following the death of their son Teddy, after which Tobias began to neglect his wife and sleep in a separate room. Meanwhile, Agnes continued living a sterile married life devoid of any feelings of love that are usually shown by couples living under the same roof. According to Stenz (1978) "if in real life the springs of motivation remain obscure, the dramatist locates the moment between two people where the descent began. As Tobias puts it, once you drop, you can come back up part of the way, but never really back again" (p.19).

However, Agnes maintained her integrity and filled her emotional vacuum by devoting all her efforts to maintaining the stability and integrity of her family. Although these plans did not work out for her, she successfully kept her family afloat, albeit informally.

The conflict and loss being suffered by Tobias are almost as great as those being suffered by Agnes. After Teddy's death, Tobias's life took a dangerous turn and he started showing his fear of death, which he felt would come to him at any moment. The biggest difficulty for Tobias is his fear and reluctance to enter another human relationship, including his marital relationship with Agnes, because of his fears of facing another loss after the death of his son. Tobias also stopped fulfilling his sexual obligations to his wife in fears of reliving Teddy's death by giving birth to another child. "For Tobias, the emotional pain was so intolerable that he could not face the possibility of another child, another loss. Unable to cope with the ultimate implication of this double vulnerability" (Stenz,1978, 77).

The erosion of marital feelings between Agnes and Tobias not only resulted in the failure of their marriage, but also directly affected their relationshp with their daughter Julia on the one hand and Julia's private life on the other. Stenz (1978) argued that "...it is impossible to discuss the effect of the death of Teddy on Julia without examining Julia's relationship with her parents" (p.76). After Teddy's death, Julia was neglected by her parents, especially by Tobias. Similar to any child of her age, Julia needed guidance and advice following the loss of her brother. She also needed parents who could watch, teach, and guide her toward the right path.

Agnes and Tobias cannot give Julia all the important things that parents must provide their child. After Teddy's death, Julia tried to fill the role of the first and only child in the family, but Tobias completely lost his interest in his daughter. He continued with this treatment of Julia even after she entered adulthood and became a wife. Each time Julia faced a failed marriage, Tobias did not even try to intervene or ask her what did not work out. In other words, the erosion of feelings between Tobias and his family has destroyed any possibility of communication among them. Each member of the family is facing a great sense of loss that prevents them from reviving their feelings of love.

\section{CONCLUSION}

Through A Delicate Balance, Albee presented an in-depth study of the anxiety, loss, denial of love, and discomfort being felt by American families. The events of the play, reveal that the principles of a happy family, including love, strong ties between parents and their children, and close relations with friends, have disappeared and have been replaced by material benefits and false social competition. Through these characters, Albee revealed that American families are linked together by their fear of their traditions and perceptions of the society.

Having a house with parents and children who are bound together by love and affection is one of the highest values that individuals aim to achieve in different societies, including the American community where people have lost their values after the Second World War. These themes are reminiscent of Albee's earlier plays, which all suggest that the aforementioned values have become false and meaningless as a consequence of the "American dream" project, which Albee has always criticized in his works.

The other important topics addressed in this play include the individuals' escape from reality, their tendency to live in a world of illusion, their anxiety, and their fear of death and madness. In A Delicate Balance, Albee chose the main characters to be over the age of 50 to reflect the state of individuals when they reach an advanced age. Albee also explored the thinking and behavior of these people and how they show their weaknesses and abandon their responsibilities. In this regard, Albee argued that "the play is basically about these people who have accommodated to their weaknesses and compromises, the adjustments they have made" (Gussow,1999, 256).

\section{REFERENCES}

[1] Adler, Ronald Brian, Lawrence B. Rosenfeld, and Russell F. Proctor. (2007). Interplay: The process of interpersonal communication. Oxford University Press, USA, 84-89.

[2] Albee, Edward. (1994). A Delicate Balance. New York: Samuel French,. Print. 
[3] Bigsby, Christopher William Edgar. (1975). Edward Albee. A Collection of Critical Essays. New Jersey: Prentice-Hall, $37-66$.

[4] Gussow, Mel. (1999). Edward Albee: A Singular Journey. New York: Simon \& Schuster, 20 -283.

[5] Kaber, Kadhim. Jingjing, Guo. (2018). "Materialist Society in Albee's Who's Afraid of Virginia Woolf?" English Language and Literature Studies, Canadian Center of Science and Education 8: 1. p110.

[6] Kaber, Kadhim. Jingjing, Guo. (2018). "Family Disintegration In Albee's The Sandbox" European Journal of English Language and Literature Studies.6:1. p 9-13.

[7] Kaber, Kadhim.Jingjing Guo. (2018). "Albee's Plays in the Light of Psychological Theories" English Language Teaching; 11: 4.p 72

[8] Nilsen, Helge N. (1989). "Responsibility, Adulthood and the Void: A Comment on Edward Albee's A Delicate Balance". Neophilologus. 6:.9. 120-157.

[9] Paolucci, Anne. (1972). From Tension to Tonic: The Plays of Edward Albee. Illinois: Southern Illinois University Press, $4-116$.

[10] Post, Robert M. (1969). “Cognitive dissonance in the plays of Edward Albee.” Quarterly Journal of Speech 55:1: 164.

[11] Roudane, Matthew C. (1987). Understanding Edward Albee. South Carolina: UP South Carolina, 113.

[12] Stenz, Anita M. (1978). Edward Albee: The Poet of Loss. New York: Mouton Publishers, 19-77.

Kadhim Hatem Kaibr was born in Maysan, Iraq in 1970. Received his M.A degree in English literature from Huazhong University of Science and Technology, Wuhan, China, 2016. Currently a Doctoral candidate at Huazhong University of Science and Technology. English department.

Jinging Guo was born in China. Currently an associate professor in the school of foreign languages at Huazhong University of Science and Technology. English department.her research interests in American literature. Dr. Guo is a member of the Chinese Association of Foreign languages teacher. 